\title{
DIVERSIFICAÇÃO DO TRABALHO RURAL: CONCEITOS E APLICAÇÕES EMPÍRICAS
}

Cicero Augusto Silveira Braga ${ }^{1}$ Marcelo José Braga²

Resumo: As formas de produção e reprodução rural vem se diversificando na medida em que os agentes econômicos precisam se adaptar a novas configurações sociais e demográficas. $O$ trabalho fora da fazenda possui um importante papel como forma de adaptação dos produtores e demais residentes de zonas rurais a esse novo contexto. As diferentes motivações e contextos nos quais a diversificação do trabalho aparece como opção faz com que novas correntes analíticas empíricas e teóricas surjam no sentido de explicar o fenômeno. Neste sentido, o presente trabalho buscou analisar em perspectiva aplicada e comparada os principais conceitos encontrados na literatura do tema, bem como as evidências empíricas.

Palavras-chave: Diversificação Agrícola. Trabalho rural. Trabalho Off-Farm. Pluriatividade. Trabalho Não agrícola.

\section{RURAL WORK DIVERSIFICATION: EMPIRICAL AND THEORETICAL FRAMEWORK}

Abstract: The productive and reproductive dynamics in rural areas have been diversifying as economic agents need to adapt to new social and demographic changes. Off-farm work plays a major role as an adaption strategy for the producers and residents in this context. Different motivations and contexts where work diversification is an option make new empirical and theoretical approaches arise to explain such phenomenon. In this sense, this work seeks to analyze in an applied and comparative perspective the main concepts found in literature, such as empirical evidence.

Keywords: Agricultural diversification. Rural work. Off-Farm work. Pluriactivity. NonAgricultural Work.

\section{DIVERSIFICACIÓN DEL TRABAJO RURAL: MARCO EMPÍRICO Y TEÓRICO}

Resumen: Las formas de producción y reproducción rural se han diversificado a medida que los agentes económicos necesitan adaptarse a las nuevas configuraciones sociales y demográficas. El trabajo off-farm juega un papel importante como medio para adaptar a los productores y otros residentes rurales a este nuevo contexto. Las diferentes motivaciones y contextos en los que la diversificación del trabajo aparece como una opción hace que surjan nuevas corrientes analíticas, empíricas y teóricas para explicar el fenómeno. En este sentido, el presente trabajo buscó analizar en una perspectiva aplicada y comparar los principales conceptos encontrados en la literatura del tema, así como la evidencia empírica.

\footnotetext{
${ }^{1}$ Universidade Federal de Viçosa, Departamento de Economia Rural, Viçosa, Brasil, ciceroaugustosb@gmail.com, https://orcid.org/0000-0002-7035-4926

${ }^{2}$ Universidade Federal de Viçosa, Departamento de Economia Rural, Viçosa, Brasil, mjbraga@ufv.br, https://orcid.org/0000-0002-8161-405X
} 
Palabras clave: Diversificación Agrícola. Trabajo Rural. Trabajo Off-farm. Pluriactividad. Trabajo No Agrícola.

\section{Introdução}

As constantes mudanças econômicas e sociais exigem que os agricultores e demais residentes do meio rural brasileiro adotem diferentes estratégias de adaptação que os assegurem na presença de choques exógenos - como os climáticos, por exemplo - ou qualquer variação não antecipada. No meio rural, notória estratégia centra-se nas possibilidades de diversificação do trabalho. $O$ interesse pelo tema na literatura inicia-se nos anos 1980 quando as medidas de renda agrícola se tornaram insuficientes para dimensionar acuradamente as receitas dos domicílios rurais, dado que suas fontes de renda e alocação de trabalho eram substancialmente variadas, considerando as diversas atividades agrícolas e não agrícolas realizadas (FULLER, 1983; ROBSON; GASSON; HILL, 1987).

Sumariamente, de acordo com Piedra-Bonilla et al. (2019), as práticas de diversificação se dividem em dois grupos: as que se são categorizadas como atividades agropecuárias e não agropecuárias - que, por sua vez, podem ser realizadas dentro da fazenda (atividades on-farm) ou fora dela (atividades off-farm). Dentre estas possibilidades, o trabalho, em suas diferentes concepções, aparece como um grupo de destaque. Por exemplo, há o exercício do trabalho rural temporário (atividade agropecuária off-farm), serviços de turismo rural (atividade agropecuária on-farm), trabalho autônomo não agrícola (atividade não agropecuária off-farm), dentre outros.

Comumente, estas práticas são tratadas como semelhantes sob diferentes sinônimos (como trabalho off-farm ou pluriatividade, por exemplo), muito embora conceitualmente se tratarem de fenômenos distintos. Vê-se, portanto, que não existe um consenso na literatura sobre as categorizações da diversificação do trabalho enquanto estratégia de adaptação para o rural dado que ele pode ser desempenhado de diferentes maneiras. A diferença, de acordo com Schneider (2009), sai do campo epistemológico e entra no campo político aplicado, especialmente na literatura internacional em que, por exemplo, é comum o uso dos termos part time farming, pluriativitè, pluriatividade, dentre outros (KIMHI, 2000; SHUCKSMITH et al., 1989).

Isto posto, o objetivo deste trabalho é apresentar diferentes correntes de análises teóricas e empíricas sobre a diversificação do trabalho rural. 
Especificamente, busca analisar as convergências dos termos, além de sua empregabilidade para análises do trabalho rural. Além disso, apresenta algumas aplicações empíricas dos diferentes termos. Este esforço gera subsídio para futuras interpretações e conceitualizações, considerando as particularidades do trabalho desempenhado. O método de análise é composto por uma exploração teórica dos distintos termos utilizados para estudar a diversificação do trabalho rural, seguida por uma busca em bases científicas das evidências empíricas dos respectivos termos explorados.

Para isso, este trabalho se estrutura em quatro itens. Após esta introdução, o segundo item é dedicado em apresentar o marco teórico do tema, considerando os diferentes termos encontrados na literatura e seus conceitos. No terceiro, são apresentadas as aplicações empíricas sobre os diferentes tipos de trabalho fora da fazenda, apontando as convergências ou não do tema. Por fim, o item final traz as conclusões da análise.

\section{Part Time Farming, Pluriatividade E Off-Farm Work: Perspectivas De Análises Teóricas}

Esta seção dedica-se em apresentar os principais termos encontrados na literatura, bem como as perspectivas teóricas por detrás de cada um. Dos conceitos apresentados, part time farming é o que aparece na literatura mais antiga sobre formas de adaptação de trabalho rural. De acordo com Sarraceno (1985), existe uma divisão histórica do conceito antes e após 1975. A princípio, o agricultor part time era aquele que, por não investir completamente na propriedade, acabava por deixar de lado as atividades agrícolas e se engajava em trabalhos não agrícolas. Este movimento podia ser entendido como uma fase transitória, à medida que a modernização da agricultora seria responsável por alterar os padrões produtivos e a agricultura se constituiria numa condição à industrialização da economia ${ }^{3}$. Superada esta fase, os part time farmers passaram a ser considerados como um verdadeiro fenômeno de interesse dos pesquisadores, excluindo a ideia de transitoriedade inicialmente proposto (SCHNEIDER, 1994).

De fato, este é um conceito que se consolida nas pesquisas sobretudo no continente europeu nos anos 1980 como um esforço dos cientistas que buscavam entender as novas dinâmicas dos trabalhadores rurais (OECD, 1978). Para o The

\footnotetext{
${ }^{3}$ Até então, o debate estava inserido especialmente sobre o papel da agricultura no desenvolvimento capitalista, gerando extensos debates e divergências.
} 
Common Agricultural Policy ${ }^{4}$, era imperativo garantir não só alimentos para toda a população, mas também soberania para os pequenos agricultores, inclusive para aqueles que exerciam outros tipos de atividades lucrativas, neste caso como atividades part time (ROBSON; GASSON; HILL, 1987).

O interesse pelo estudo do campo inicia quando as formas de medida disponíveis eram insuficientes para avaliar a extensão dos problemas e particularidades relacionados à renda agrícola. No contexto da Inglaterra, Robson, Gasson e Hill (1987) observaram que o gap presente nas medidas oficiais era, em grande parte, suprido pelas atividades de part time farming, considerando as nonfarming earnings ${ }^{5}$, pensões e investimentos que, em grande parte dos casos, a renda média era superior quando comparado com famílias full-timers.

Este termo, por si só, apresenta outras subdivisões, bem como part time farm, part time farmer e part time farming em que os pesquisadores assumiam uma correlação causal entre si. De acordo com Fuller (1990), na maioria dos estudos até 1980, os pesquisadores classificavam aqueles agricultores que exerciam algum tipo de trabalho fora da propriedade como part time farmers, enquanto suas operações faziam parte do grupo de atividades part time farm. Independente da função exercida, ou da coexistência de trabalhos fora da propriedade, exercer qualquer tipo de trabalho não agrícola classificaria a atividade como part time farming, enquanto aqueles que exerciam funções exclusivamente on-farm eram considerados "full-time farmers".

Existem, portanto, dois temas chaves na caracterização de part time farming: i) o termo não se refere à uma análise das relações domiciliares, mas sim como uma estratégia do domicílio como um todo analisada a partir da pessoa de referência do domicílio e; ii) a existência de uma dualidade em que ou toda a renda do domicílio é advinda de trabalhos agrícolas (full time farming) ou existe algum complemento externo, neste caso caracterizado como part time farms, independente da parcela de renda gerada ou tempo dedicado às outras atividades em relação ao trabalho estritamente agrícolas.

Consequentemente, na medida em que se avançam os estudos sobre o tema, sua complexidade vem à tona e o termo deixa, então, de conseguir captar todas as dimensões do fenômeno. Isto porque, em alguns estabelecimentos, a renda de

\footnotetext{
${ }^{4}$ Política comum da União Europeia criada em 1962 que tem por objetivo criar políticas de desenvolvimento agrícola para os países membros.

${ }^{5}$ Neste contexto, o termo aparecia dentro da discussão do part time farming como referência ao termo de rendas não agrícolas, que toma corpo como um conceito para análise posteriormente.
} 
trabalhos considerados part time farming era insignificante quando analisada a renda total do domicílio. Além disso, o simples exercício de outra atividade que não estivesse diretamente relacionada com a produção agrícola do domicílio, já o caracterizava como part time farmer, mesmo quando as atividades agropecuárias eram operadas com sua totalidade e eficiência. Assim, a conotação negativa que o termo ganhou, como descreveram Bryden e Fuller (1988), fez com que a atenção de pesquisas e políticas se dissolvessem, urgindo a necessidade de ampliação do conceito.

O debate no campo de part time farming foi estendido por Kimhi (2000), que estudou se este seria um fenômeno estável e recorrente para agricultores ou significaria uma mudança sistemática do trabalho rural como uma saída de atividades predominantemente agrícolas. O autor encontrou que os agricultores consideravam a realização de atividades off-farm, ou seja, aquelas realizadas fora do próprio estabelecimento, no longo prazo como uma forma de adaptação e complementação de rendas, combinando atividades dentro e fora da propriedade.

Isto posto, o termo part time farming que estava limitado a uma generalização para aqueles agricultores que ou estavam em um processo transacional de substituição das atividades agrícolas, ou que exerciam atividades agrícolas como um "hobby" dos agricultores que estavam menos comprometidos para a agricultora como principal atividade lucrativa. É a partir daí que a discussão começa a considerar diferentes formas de trabalho e renda rural, surgindo termos como Multiple Job-Farm Households ou, ainda, Other Gainful Activities que, posteriormente, se consolida no debate da pluriatividade (CARTER, 1997; SCHNEIDER, 2009), como será aqui apresentado. Neste mesmo contexto, outros termos, apesar de menos frequentes, são encontrados na literatura para caracterizar indivíduos que eram obrigados a inserir-se em outras formas de ocupação não agrícola, bem como five o'clock farming, worker-peasant, que fazem alusão à condição dos trabalhadores que, num cenário de industrialização, dividiam a vida no campo, com trabalho assalariado no interior das fábricas (ANJOS, 2001).

Entendendo que o conceito a priori utilizado como trabalhadores de tempo parcial na agricultura (part time farmers) era limitado, sociólogos e economistas desprenderam um esforço no campo epistemológico no intuito de captar o dinamismo das relações de trabalho rural e as distintas particularidades dos fenômenos. Não obstante, no período de amadurecimento do conceito, os termos part time farming e pluriactivité coexistiam na literatura, uma vez que os limites 
teóricos estavam ainda se desenvolvendo. A distinção do termo, outrora utilizados como sinônimos, era que enquanto o primeiro era principalmente encontrado na literatura inglesa, o último estava nos estudos de língua francesa (CARNEIRO, 1996).

A fim de estabelecer um rompimento com a conotação negativa do termo, para Carter (1997), a pluriatividade deveria ser entendida como parte da evolução do uso de recursos de base rural por parte dos agricultores e não somente como um comportamento atípico - ou hobby. Esta definição traria maior respaldo para o termo e permitiria extrapolações nas inferências sobre o mercado de trabalho de agricultores ou residentes do meio rural. Definitivo para estabelecimento do termo pluriatividade como superação teórica, pode ser apontado a criação do Arkleton Trust Project6, formado por países que compunham a Comunidade Econômica Europeia (CEE). Os estudos financiados pela instituição buscavam estudar unidades domiciliares que combinavam as atividades agrícolas com outras atividades, a partir daí já as assumindo como pluriativas. Esta afirmação temática coloca a pluriatividade como possibilidade de análise da coexistência de distintas formas de trabalho e rendas dos domicílios rurais (SCHNEIDER, 2009), fugindo da dualidade part time e full time.

A pluriatividade, segundo Newby (1988), permite uma abordagem mais holística para entendimento dos meios de reprodução das famílias rurais. Isto porque as famílias, como unidade coletiva de consumo, se relacionam com as diferentes possibilidades de reprodução social, considerando oportunidades externas, algumas das quais podem estar na agricultura e outras não. Ademais, considera que existem relações sociais internas como a divisão do trabalho de modo que é possível se organizarem para maximização de sua utilidade conjunta (BRYDEN; FULLER, 1988; NEWBY, 1987). Neste sentido, como aponta Lima (2008), a pluriatividade constitui-se como uma estratégia para fortalecimento da economia familiar rural, na medida em que possibilita a expansão da propriedade e aquisição de ativos.

Complementarmente, Escher et al. (2015) observaram a partir dos dados do Censo Agropecuário de 2006 duas possíveis tipologias para a pluriatividade. A primeira delas, diz respeito à "pluriatividade intersetorial", que é oriunda das relações da agricultura com indústria, comércio e serviços, e outras transformações

\footnotetext{
${ }^{6}$ Fundada em 1977, a instituição fornece financiamento para pesquisadores dos diversos temas relacionados ao desenvolvimento rural. Ver mais em: https://arkletontrust.co.uk/.
} 
estruturais do mercado de trabalho, como a descentralização industrial, mudanças nas relações laborais e fluxo migratório pendular. A segunda tipologia é definida como pluriatividade agrária e está relacionada com as possibilidades de combinações de atividades dentro do próprio setor agropecuário, como demanda por serviços complementares (aluguel de capital, contratação de serviços, terceirização, etc.) ou, ainda, uma forma de atividade para-agrícola, quando parte da produção de subsistência passa a ser destinada à venda (surgimento das chamadas agroindústrias familiares rurais). Esta última é mais passível de ocorrência especialmente naquelas regiões em que as ocupações são predominantemente agrárias.

Finalmente, a pluriatividade é estabelecida como um modo produtivo em que são considerados tanto a agricultura como outros tipos de atividades não necessariamente relacionadas a ela, dentro ou fora do estabelecimento. Além disso, considera a possibilidade de outras formas de rendas como aposentadorias, trabalhos externos, etc. Não surpreendentemente, na literatura mais recente o conceito tem incorporado diferentes definições e aplicações e este termo se estabelece como um verdadeiro avanço conceitual do tema ao passo que a unidade de análise deixa de ser a pessoa responsável da família (ou chefe do domicílio) e torna-se uma decisão coletiva domiciliar (ESCHER et al., 2015).

Deve-se ressaltar que o termo, originado em discussões na literatura de países desenvolvidos - sobretudo europeus -, apesar de assumir um conceito amplo, é marcada por aspectos regionais na medida em que os pressupostos teóricos avançam e as distintas formas de exercício destas atividades são analisadas (SCHNEIDER, 2003). Assume-se, portanto, que a pluriatividade não é um fenômeno único e pode se manifestar a partir de diferentes formas, motivada por diferentes fatores, especialmente pelas particularidades e dinâmicas locais do mercado de trabalho rural. Estas nuances serão explicitadas na seção 3, em que se apresentam suas aplicações empíricas.

Viu-se que, por um lado, o exercício da pluriatividade se apresenta como opção para as unidades domiciliares complementarem renda e aquisição de novos ativos ou, ainda, empregarem mão de obra excedente em outras formas produtivas. Por outro lado, as transformações do meio rural, incluindo dinâmicas sociais, demográficas e do mercado de trabalho, faz com que os produtores não consigam se inserir na lógica de reprodução com atividades exclusivamente agrícolas. Como pontua Neves (1997), a expansão e consolidação da pluriatividade depende de 
contextos específicos e que haja convergência entre modos de organização do mercado de trabalho.

Contudo, a inexistência de condições adequadas para o exercício concomitante de atividades agrícolas e não agrícolas pode gerar uma expulsão de trabalhadores rurais das atividades agrícolas, que passam a exercer, em sua totalidade, atividades exclusivamente não agrícolas. Neste caso, o termo pluriatividade ainda não consegue captar completamente fenômeno de trabalhadores rurais não agrícolas. Cria-se, portanto, uma nova categoria analítica do tema, que se dedica a estudar os trabalhos e atividades exclusivamente não agrícolas realizadas por trabalhadores rurais.

Estas atividades exclusivamente não agrícolas, ou mesmo o exercício da pluriatividade, são abarcadas, quase em sua totalidade, no grupo dos trabalhos fora da fazenda, ou o off-farm work. De fato, o termo off-farm work aparece como um marco teórico que, por um lado, por dizer respeito à todas as atividades realizadas fora da fazenda - sobretudo as não agrícolas - é capaz de explicar os dinamismos do trabalho rural e suas novas configurações. Por outro lado, esta generalização acaba por restringir diferentes análises, uma vez que parte das estatísticas especificamente rurais consideram somente as atividades que são realizadas dentro dos próprios estabelecimentos, bem como apontou Kimhi (1994). Neste sentido, é comum que os modelos teóricos que consideram as atividades não agrícolas ou formas de diversificação das atividades agropecuárias utilizem o termo off-farm work (HUFFMAN, 2006; HUFFMAN; LANGE, 1989; SUMNER, 1982).

De maneira geral, o trabalho off-farm tem diferentes objetivos $\mathrm{e}$ consequências. Os membros da família que buscam trabalhos off-farm, bem como explicitaram Bryden e Fuller (1988), não são vistos como diletantes, mas sim como indivíduos que exercem uma escolha de novas carreiras ou fontes extras de renda. Contudo, sobretudo para pequenos agricultores, a pequena escala de produção exige rendas complementares que não são possíveis no contexto da produção no próprio estabelecimento para que sejam mantidos padrões de vida locais, de modo que a inserção em atividades off-farm passa a ser necessidade e não mais uma escolha.

Isto posto, o trabalho off-farm por também compreender outros fenômenos apresentados como fonte de diversificação e adaptação agropecuária, pode atuar a partir de diferentes formas e impactar outcomes das famílias rurais positiva e negativamente. Start (2001) sumarizou alguns dos mecanismos e impactos pelos 
quais o trabalho off-farm afeta o bem-estar dos indivíduos e famílias em suas diferentes dimensões, bem como apresentado no Quadro 1:

Quadro 1 - Mecanismos, dimensões e impactos do trabalho rural off-farm sobre o bem-estar

\begin{tabular}{|l|l|l|l|}
\hline \multicolumn{1}{|c|}{ Mecanismo } & \multicolumn{1}{|c|}{$\begin{array}{c}\text { Dimensão de } \\
\text { bem-estar }\end{array}$} & Impactos Negativos & \multicolumn{1}{c|}{ Impactos Positivos } \\
\hline $\begin{array}{l}\text { Trabalho em } \\
\text { setores de baixo } \\
\text { retorno }\end{array}$ & Renda & $\begin{array}{l}\text { Baixos retornos e } \\
\text { possibilidade de } \\
\text { superação da } \\
\text { pobreza. }\end{array}$ & $\begin{array}{l}\text { Atua para verificar queda } \\
\text { dos salários agrícolas. }\end{array}$ \\
\hline $\begin{array}{l}\text { Muitos são } \\
\text { informais, sem } \\
\text { regulação e longe } \\
\text { do domicílio }\end{array}$ & $\begin{array}{l}\text { Condições de } \\
\text { trabalho }\end{array}$ & $\begin{array}{l}\text { Baixo padrão de } \\
\text { trabalho; } \\
\text { Estresse de viajar e, } \\
\text { ou, morar longe do } \\
\text { domicílio rural. }\end{array}$ & $\begin{array}{l}\text { Atua como uma } \\
\text { estratégia de } \\
\text { enfrentamento e } \\
\text { segurança a possíveis } \\
\text { choques. }\end{array}$ \\
\hline $\begin{array}{l}\text { Diversificação das } \\
\text { possibilidades } \\
\text { não-agrícola, com } \\
\text { setores mais } \\
\text { lucrativos }\end{array}$ & Desigualdade & $\begin{array}{l}\text { Exclui aqueles sem } \\
\text { acesso aos recursos } \\
\text { (como os menos } \\
\text { educados, por } \\
\text { exemplo). }\end{array}$ & $\begin{array}{l}\text { Possibilita crescimento } \\
\text { regional, alcançando os } \\
\text { mais pobres a partir das } \\
\text { externalidades. }\end{array}$ \\
\hline $\begin{array}{l}\text { Mercado de } \\
\text { trabalho informal }\end{array}$ & Segurança & $\begin{array}{l}\text { Instabilidade no } \\
\text { emprego e } \\
\text { dificuldade de ações } \\
\text { coletivas. }\end{array}$ & $\begin{array}{l}\text { Eficiente para o comércio } \\
\text { e crescimento, permitindo } \\
\text { maior flexibilidade ao } \\
\text { grau de subsistência. }\end{array}$ \\
\hline $\begin{array}{l}\text { Trabalho de } \\
\text { mercado e } \\
\text { oportunidades } \\
\text { não-locais }\end{array}$ & $\begin{array}{l}\text { Empoderamento } \\
\text { social e político }\end{array}$ & $\begin{array}{l}\text { Trabalho migratório } \\
\text { pode ser disperso, } \\
\text { reduzindo barganha e } \\
\text { desestabilizando } \\
\text { direitos civis. }\end{array}$ & $\begin{array}{l}\text { Permite oportunidades } \\
\text { para experiências sociais } \\
\text { e econômicas não rurais. } \\
\text { Pode influir em novas } \\
\text { experiências, habilidades, } \\
\text { contatos e quebra de } \\
\text { estruturas tradicionais. }\end{array}$ \\
\hline
\end{tabular}

Fonte: Adaptado de Start (2001).

No Quadro 1 cinco mecanismos são apresentados como formas de impactos do trabalho off-farm sobre o bem-estar. Naturalmente, cada um destes mecanismos associa-se com impactos positivos ou negativos sobre os indivíduos. Pelo lado positivo, bem como mostrou Start (2001), as rendas off-farm conseguem aumentar a renda per capita do domicílio e conseguem estabelecer novas estratégias para o gerenciamento de custos e riscos dos estabelecimentos agrícolas, especialmente frente a choques externos. Além disso, consegue garantir uma renda que não é sazonal, diferentemente da produção em pequena escala. O trabalho off-farm, ainda, apoia o crescimento agrícola diminuindo restrições da oferta e impacta no crescimento e desenvolvimento da região. Ao estabelecer novos parâmetros, os indivíduos buscam novas oportunidades que podem traduzir-se em um maior desenvolvimento rural. 
Por outro lado, entendendo que as atividades passam, em alguma medida, por um setor residual ou com baixos retornos, a ideia de "rede de segurança" como possíveis choques camufla a real condição dos empregos aos quais os indivíduos podem se submeter (ambientes exploradores, com rendas baixas e com um custo de deslocamento atrelado). Estes baixos retornos, associam-se às desigualdades estruturais, uma vez que as possibilidades de ascensão social podem estar condicionadas à um processo migratório, por exemplo. Ademais, os meios de subsistência das atividades não agrícolas são mais inseguros dadas as dinâmicas dos mercados de trabalho, além de dispersos setorialmente, diminuindo possibilidades de ações coletivas ou "voz política".

Não somente os trabalhos, mas também as rendas da diversificação do trabalho são oriundas de distintas atividades. Resumidamente, de acordo com Kautsky (1980), os trabalhadores rurais podem receber rendas originárias de ocupações acessórias. A primeira delas, e a de mais fácil acesso, é o trabalho agrícola assalariado, que era realizado desde as relações feudais, hoje manifestada por trabalho de pequenos agricultores para aqueles com maior capacidade produtiva, sobretudo em períodos específicos como colheitas, por exemplo ${ }^{7}$. A segunda manifestação observada pelo autor é a de indústria em domicílio, que se desenvolve especialmente em lugares menos propícios para o desenvolvimento agrícola em termos naturais e/ou técnicos. Apesar de ser predominante em um período que antecede a industrialização de atividades rurais, ela ainda pode ser observada atualmente por meio de prestações de serviços específicos. Por fim, o autor pontua as indústrias modernas, que permite o exercício de tarefas complementares, especialmente para os pequenos agricultores.

Ainda, Schneider (2011) enumerou cinco tipos de fonte de rendas: renda agrícola, transferência social, rendas de outras fontes, outras fontes de renda e renda de atividades não agrícolas. O autor explica que a composição da renda da família, além de refletir os resultados da ocupação, é resultante dos rendimentos obtidos pela aposentadoria, pensão, juros, arrendamentos, doação e aluguéis. Nesse sentido, ao entender o papel da diversificação do trabalho rural, faz-se necessário observar que os rendimentos dos domicílios rurais são plurais e oriundos de fontes que podem ser produtivos ou não.

\footnotetext{
${ }^{7}$ Neste ponto, pode-se também entender a discussão da diversificação agrícola, em que produtores com maior capacidade de diversificar as culturas, possui mais chances de produção por todo o ano, considerando sazonalidades.
} 
Sumariamente, na Figura 1 ilustra-se a discussão contida nesta seção considerando as formas de manifestação teóricas das possibilidades da diversificação do trabalho rural, aqui sintetizadas sobre o termo off-farm, bem como os tipos de atividades e rendimentos provenientes das atividades a serem exercidas.

Figura 1 - Trabalho Off-Farm, manifestações teóricas, atividades e rendas.

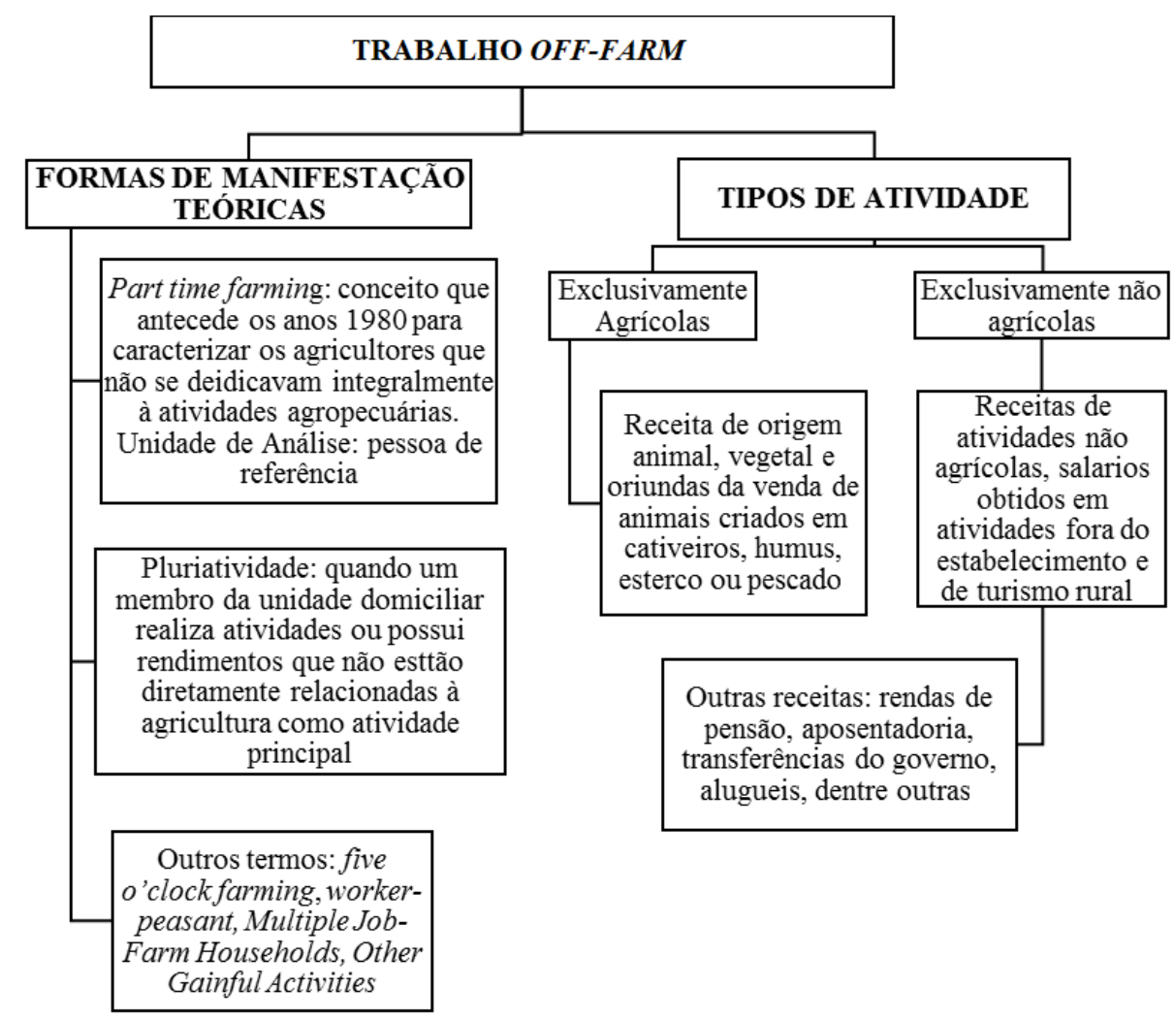

Fonte: Resultados da pesquisa.

Estas várias relações e possibilidades da diversificação do trabalho, como apontado, agem de acordo com o ambiente que se inserem e as condições de reprodução do mercado de trabalho local. Desta forma, na próxima seção apresentam-se evidências empíricas de como o trabalho off-farm, pluriatividade ou part time farming são postos como mecanismos de mudanças e impactos nos diferentes outcomes do meio rural.

\section{Aplicações Empíricas}

Apresentados os principais conceitos, nesta seção busca-se realizar um breve levantamento da literatura das relações dos diferentes tipos de trabalho e suas implicações. Ressalta-se que esta seção não se dedica em uma revisão sistemática da literatura, mas sim compilar algumas evidências chave que subsidiem as análises e reforcem as diferenças aplicadas dos termos apresentados na seção anterior. 
Os resultados aqui apresentados foram pesquisados em diferentes bases de dados como o Google Scholar e a SciELO (Scientific Electronic Library Online) usando como descritores os termos apresentados anteriormente. Também se buscou, a partir das referências bibliográficas dos artigos analisados, notas técnicas, comunicados oficiais e páginas de agências governamentais que tratassem sobre os temas em algum contexto específico. O critério de inclusão foi definido a partir do caráter do trabalho, ou seja, se traziam evidências aplicadas ou não. Ao final da seção, na Tabela 2, sintetiza-se os principais resultados, os respectivos autores e localidade dos estudos performados.

Uma vez que, como anteriormente pontuado, o conceito de part time farming tem recorte local histórico, as aplicações empíricas na literatura que se debruçaram sobre o tema possuem esta limitação. Neste sentido, Cavazzani e Fuller (1982), considerando diferentes formas e estágios de desenvolvimento das sociedades em que ocorre, agregam diferentes casos deste fenômeno em três grupos principais. $O$ primeiro, diz respeito a sociedades industriais avançadas, em que o part time farming é considerado uma característica estrutural. Os autores apontam que, na América do Norte, este tipo de agricultura é um fenômeno de organização racional dos agricultores que tem acesso à diferentes fontes de renda. Aqui, os autores pontuam que o trabalho de meio período parte da combinação de alocação de recursos de diferentes membros da unidade domiciliar e, portanto, esta forma agregada deveria ser a unidade de análise. Rompe, portanto, com o pressuposto do part time farming que, posteriormente, passa a ser considerado no campo da pluriatividade, em que a análise é baseada na família como um todo e não só no chefe de domicílio.

Dentre as sociedades industriais desenvolvidas, no Japão o fenômeno aparecia substancialmente diferente se comparado EUA e Canadá. Neste país, os part time farmers operam em um status de estabilidade, dado que implica em uma melhor utilização dos recursos domiciliares. O autor faz ligação com alguns países europeus, que possuem características similares na relação entre agricultura e indústria. Esta diferenciação é o que as leva a estudarem sociedades então recentemente industrializadas. Reforça, sobretudo, a importância de se analisarem os casos a partir das particularidades do trabalho realizado.

Nesse sentido, Cavazzani e Fuller (1982) mostraram que mesmo nos países da Europa em que a agricultura possuía um papel central na economia, a diversificação de trabalho possuía padrões específicos em cada um. Existe, porém uma 
característica comum nestes países em que as mulheres tendiam a substituir o trabalho masculino na agricultura nos casos em que os homens passavam a trabalhar nas fábricas. Inversamente, em um recente estudo para pequenos agricultores na Itália, Tocco, Davidova e Bailey (2016) encontram que nas famílias pluriativas, as mulheres tendem a trabalharem mais em trabalhos off-farm que os homens. É interessante pontuar que ainda aqui, as autoras ainda usam o termo part time farming, referido como um termo que representa menor nível de desenvolvimento da região e, a posteriori, tratando-o como sinônimo de multiple job holding e pluriatividade. As autoras encontram, ainda, que o tamanho da propriedade é importante para determinar a estrutura laboral dos agricultores na região.

Por fim, Cavazzani e Fuller (1982) apresentam os resultados para as economias em desenvolvimento das quais não haviam muitas evidências. Os autores apontam que o part time farming era marcado por uma divisão de classes em países latinoamericanos e africanos. Por um lado, os agricultores que se inseriam em atividades off-farm, o faziam por necessidade de sobrevivência, dado que sua produção não era suficiente para subsistência. Por outro lado, para os donos de terra que contratavam estes agricultores, a prática era entendida como um privilégio. Das experiências pontuadas nos três tipos de sociedade, esta dualidade de países em desenvolvimento é a que mais se aproxima do entendimento inicial do termo, que tratava os part time farmers como agentes inseridos em uma lógica que a agricultura não era suficiente para reprodução social (GASSON, 1986).

Em trabalho pioneiro sobre os impactos do part time farming, Munton, Whatmore e Marsden (1989) analisam as implicações das atividades para o panorama rural. Os autores mostram que, mesmo dentro de uma amostra restrita para o Sul da Inglaterra, qualquer generalização deve ser cuidadosa. As muitas variações observadas são oriundas especialmente da forma com que o trabalho é exercido, seja ele na relação de tempo dedicado ou ainda de quem o performa. A partir daqui fica nítido, portanto, que apesar de existir um limite conceitual para os termos, suas aplicações podem coexistir quando o objetivo é analisar impactos da performance de trabalhos off-farm.

Este desafio é posto na literatura mais recente especialmente para o tratamento de dados secundários. Dado que, dentro de um domicílio, é comum que diferentes indivíduos exerçam diferentes atividades, a maior parte dos domicílios rurais poderiam ser, portanto, considerados pluriativos, exigindo cuidados em sua 
categorização e surgindo diferentes formas de diferenciação prática. Neste sentido, Silva, Freitas e Costa (2018) estabeleceram um threshold para determinar os efeitos pluriatividade sobre a eficiência técnica dos domicílios brasileiros, baseando na renda média do domicílio: a unidade produtiva que apresentasse uma razão das rendas de atividades performadas on-farm e off-farm igual à média mais um desvio padrão, eram caracterizadas como pluriativas. Os resultados, estimados com dados do Censo Agropecuário, mostraram que os estabelecimentos que se dedicavam a atividades exclusivamente agrícolas eram tecnicamente mais eficientes.

Similarmente, Haiguang, Xiubin e Jiping (2013) classificaram as famílias chinesas em quatro classes de acordo com a participação da renda de trabalhos não agrícolas sobre a renda total domiciliar. Os domicílios podiam ser considerados como full time farming households, quando a proporção de rendas não agrícolas era menor que 5\%, part-time farming households I (entre 5\% e 50\% de rendas não agrícolas), part-time farming households II (entre 50\% e 95\% de rendas não agrícolas) e, finalmente, non-farm households quando mais $95 \%$ da renda era não agrícola. Ou seja, os autores consideram qualquer tipo de trabalho off-farm não agrícola que combinado ou não com rendas agrícolas (pluriatividade), classificavam o domicílio como full ou part time farming.

Rocha (2017) estendeu o conceito de unidade domiciliar para levantamento de dados primários e caracterização da pluriatividade no sudoeste Baiano. A autora considerou como família pluriativa aquele "grupo social que mantém laços de parentesco e consanguinidade na mesma propriedade, e que estabelecem entre si um nível de confiança, igualdade e cooperação" (ROCHA, 2017, p. 222). Com isto, conseguiu analisar as unidades produtivas a partir dos membros que nela trabalham, mas não necessariamente habitam, como é grande parte dos casos dos filhos dos agricultores que casam e formam outro núcleo familiar.

Observar esta particularidade não seria possível utilizando dados secundários como o Censo Agropecuário, por exemplo. Isto porque, uma vez que analisam as unidades domiciliares e seus indivíduos separadamente, os dados não são suficientes para tal inferência. Por exemplo, para analisar os condicionantes e diferenciais de renda de famílias pluriativas e não agrícolas com dados da PNAD, Sakamoto, Nascimento e Maia (2016) determinam que as famílias pluriativas seriam “aquelas que contém pelo menos um membro ocupado em atividade agrícola e pelo menos um membro ocupado em atividade não agrícola" (p. 6). Entretanto, para fazer tal categorização, os autores são genéricos ao definirem a variável de interesse. 
Nomeadamente, para determinar famílias como agrícolas, consideraram que todos os integrantes do domicílio, excluindo empregados que moravam no local, exerciam funções agrícolas. Ainda, desconsideraram os trabalhos secundários dos indivíduos, levando em conta apenas o trabalho principal. Neste caso, indivíduos que exerciam trabalhos agrícolas off-farm ou, ainda, exerciam outra atividade como trabalho secundário, estavam excluídas da classificação de pluriativos.

De fato, a utilização de dados secundários pode exigir que algumas flexibilidades sejam adotadas para realização de análises estatísticas. Assim, Escher et al. (2015) descrevem minuciosamente os cuidados adotados com a base de dados do Censo Agropecuário no intuito de categorizarem os domicílios da maneira mais factível possível. Os autores explicam que escolheram, dentre as perguntas, sobre o exercício de alguma atividade remunerada fora do estabelecimento agropecuário por parte do produtor ou algum membro da família. Esta escolha, como bem pontuam, possivelmente leva a uma subestimação dos estabelecimentos pluriativos uma vez que exclui o exercício de atividades não agrícolas dentro do domicílio.

Ainda, confirmando que a pluriatividade é um fenômeno com recorte espacial e histórico, Rocha (2017) mostra que a pluriatividade das famílias analisadas se dá majoritariamente pelo exercício concomitante de atividades agrícolas na propriedade e trabalhos não agrícolas fora da mesma. A autora explica que existe um espiral que impulsiona as famílias para realização das atividades off-farm, que se inicia com a seca e a impossibilidade de produção, seguida pela dificuldade no acesso a políticas públicas, reduzindo a especialização com as práticas agrícolas, levando às famílias terem atitudes empreendedoras, dada a renda agrícola insuficiente.

Por sua vez, Lima (2008) utiliza de três categorias para analisar os trabalhos realizados pelas famílias, bem sendo pluriativas, exclusivamente agrícolas ou exclusivamente não agrícolas. $O$ autor encontra que fontes de renda exclusivamente não agrícolas e pluriatividade seriam responsáveis para a redução da pobreza e desigualdade rural no Nordeste brasileiro. Resultados semelhantes foram encontrados por Moreira (2010) na Região Sudeste. Similarmente, Ney e Hoffmann (2008) analisam os impactos de rendas agrícolas e não agrícolas para a desigualdade de renda do Brasil sem, contudo, considerar a discussão da pluriatividade. Os autores mostram que se, por um lado, as ocupações agrícolas são responsáveis pela redução das disparidades de renda, aquelas exclusivamente não agrícolas, na verdade, pioram a situação. 
De maneira geral, a ascensão a mercados de trabalho não agrícolas possui diferentes motivações e impactos. De acordo com Yang (1997), o trabalhador mais educado pode tomar decisões quando trabalha off-farm gerando um efeito spillover para outros membros da família que afeta os níveis educacionais destes. O efeito positivo do trabalho off-farm sobre a educação é confirmado por Neudert et al. (2015) que mostram, ainda, que a diversificação do trabalho agrícola afeta também a riqueza do domicílio e o bem-estar auto reportado em Madagascar. No Nepal, Gautam e Andersen (2016) criaram um índice subjetivo de bem-estar composto de consumo alimentar, ativos domiciliares, poupança e acesso ao crédito. Os resultados mostram que não só a diversificação de trabalhos agrícola por si só afeta o bem-estar, mas sim os ganhos monetários advindos da mesma.

Ainda, o exercício de trabalho off-farm possui implicâncias para a alocação de recursos intradomiciliares além de recorte de gênero. Gasson (1984) mostra a importância da inserção das mulheres no mercado de trabalho que, na década de 1980 "saíam para trabalhar" e que agricultores se casavam mais com mulheres que cada vez mais tinham background não agrícola, configurando, portanto, os domicílios como part time farms. Posteriormente, a autora mostra que o fenômeno era responsável por alterar as relações de gênero e alocação de tempo dedicado nas atividades domésticas. Por um lado, esta relação é resultado de uma estratégia de empoderamento, mas por outro aumentava as atribuições das mulheres nos domicílios - aqui já entendidos como pluriativos (GASSON; WINTER, 1992).

Além disso, o estudo de bem-estar e trabalho off-farm, em suas diversas naturezas possuem um viés de gênero, uma vez que afetam homens e mulheres de maneiras diferentes. Neste sentido, Bagachwa e Stewart (1992) reforçam que, mesmo que as atividades não agrícolas tendem a ser mais igualitárias em relação àquelas industriais para homens e mulheres os impactos na renda podem ser diferentes. Sugere-se, portanto, que as barreiras de entrada ao trabalho não agrícola remunerado são ainda maiores para as mulheres. Uma das barreiras encontradas é referente à seletividade educacional. Ao analisar o bem-estar auto reportado, Van den Broeck e Maertens (2017) mostram que a renda off-farm afeta principalmente as mulheres mais pobres no Senegal. Entretanto, para as mulheres acima da linha da pobreza existe um efeito negativo associado a sobrecarga de trabalho e insatisfação com a atividade exercida.

A relação do off-farm e implicações numa perspectiva de gênero foram ainda analisadas por Su et al. (2016) que mostraram que na China não há evidências para 
uma feminização da agricultura mas, sim, uma maior inserção dessas em atividades off-farm. Complementarmente, Perry e Ahearn (1994) apontaram um processo histórico da contribuição das mulheres nas rendas domiciliares rurais, sobretudo quando combinadas atividades dentro e fora do domicílio. Na Amazônia Brasileira, Vanwey e Vithayathil (2013) mostraram que o trabalho off-farm é distinto entre homens e mulheres dado que atividades reprodutivas e produtivas no meio rural possuem particularidades que afetam diferentemente os indivíduos.

Ainda, o uso do termo off-farm work (usualmente associado às dicotômicas rendas agrícolas e não agrícolas) é o mais comum quando propostas abordagens teóricas de análises da diversificação do trabalho. Por exemplo, Sumner (1982) modelou os efeitos do trabalho off-farm sobre a oferta de trabalho agrícola, mostrando que este tipo de trabalho é substancialmente sensitivo a incentivos econômicos. Já Huffman (2006) analisou como a decisão de realização de trabalho off-farm nos domicílios é influenciada pelo capital humano adquirido. Este autor analisou, ainda, como a decisão de inserir-se em atividades do tipo é tomada quando considerado o núcleo familiar formado de marido e mulher, de modo que a decisão individual é diretamente afetada quando o (a) parceiro (a) realiza trabalho off-farm (HUFFMAN; LANGE, 1989).

Viu-se, portanto, que o termo part time farming é quase majoritariamente encontrado na literatura dos anos 1980, quando o termo surge. Após isso, alguns autores fazem o esforço para definições de pluriatividade que atendam critérios objetivos da pesquisa. Como bem apontam Soares e Peixinho (2019), os termos que são próximos distinguem-se pelo fato de que enquanto o primeiro trata pela prática de atividades não agrícolas realizadas pelo responsável pelo domicílio, ou seja, o chefe de família, a pluriatividade considera a prática de qualquer membro, tornando a unidade de observação, portanto, a nível domiciliar.

Sumariamente, vê-se o avanço teórico iniciado na literatura francesa que buscava analisar as novas formas de organização do trabalho familiar a partir de atividades não agrícolas, cunha o termo da pluriactivitè ou, pluriatividade. A partir daí, especialmente na literatura americana, a diversificação do trabalho rural incorpora o tema a partir das atividades realizadas fora dos estabelecimentos cunhado pelo off-farm work. $\mathrm{O}$ avanço das pesquisas no tema faz com que o termo off-farm work se popularize e se estabeleça como uma espécie de "guarda-chuva" para análises do trabalho rural não agrícola, bem como mostrado na Figura 1. 
Por fim, no Quadro 2, sumariza-se os trabalhos analisados nesta seção, apresentados por ordem cronológica. No Quadro, encontra-se o termo empregado, a unidade de análise utilizada, bem como o local analisado e os principais resultados. 
Quadro 2 - Autores, termo, local e principais resultados encontrados na revisão da literatura por ordem cronológica

\begin{tabular}{|c|c|c|c|c|}
\hline Autores (as) & $\begin{array}{l}\text { Termo } \\
\text { Empregado }\end{array}$ & Unidade de análise & Local & Resultados Apresentados \\
\hline Cavazzani e Fuller (1982) & $\begin{array}{l}\text { Part time } \\
\text { farming }\end{array}$ & Indivíduo/Estabelecimento & Mundo & $\begin{array}{l}\text { Apresentam a perspectiva internacional } \\
\text { para o tema, comparando sociedades } \\
\text { industriais desenvolvidas e em } \\
\text { desenvolvimento }\end{array}$ \\
\hline Sumner (1982) & $\begin{array}{l}\text { Off-Farm } \\
\text { Work }\end{array}$ & Indivíduo & Teórico & $\begin{array}{l}\text { Modelos desenvolvidos para examinar } \\
\text { os salários fora da fazenda, a } \\
\text { participação da força de trabalho e as } \\
\text { horas de trabalho dos trabalhadores }\end{array}$ \\
\hline Gasson (1984) & $\begin{array}{l}\text { Off-Farm } \\
\text { Work }\end{array}$ & Individuo & Europa & $\begin{array}{l}\text { Efeitos do Trabalho off farm para } \\
\text { mulheres na Europa e sua importância } \\
\text { para questões de gênero }\end{array}$ \\
\hline Gasson (1986) & $\begin{array}{l}\text { Part time } \\
\text { farming }\end{array}$ & Indivíduo/Estabelecimento & Inglaterra & $\begin{array}{l}\text { Dualidade do termo part time farming } \\
\text { em países desenvolvidos e agricultura } \\
\text { como insuficiente para garantia de } \\
\text { reprodução social }\end{array}$ \\
\hline Munton, Whatmore e Marsden (1989) & $\begin{array}{l}\text { Part time } \\
\text { farming }\end{array}$ & Estabelecimento & Inglaterra & $\begin{array}{l}\text { Implicações do part time farming sobre } \\
\text { o panorama rural }\end{array}$ \\
\hline Huffman e Lange (1989) & $\begin{array}{l}\text { Off-Farm } \\
\text { Work }\end{array}$ & Individuo & Teórico & $\begin{array}{l}\text { Como a decisão de realizar trabalho off- } \\
\text { farm é afetada quando a decisão é } \\
\text { conjunta de maridos e mulheres. }\end{array}$ \\
\hline Bagachwa e Stewart (1992) & $\begin{array}{l}\text { Atividades } \\
\text { não agrícolas }\end{array}$ & Indivíduo/Estabelecimento & $\begin{array}{l}\text { África Sub } \\
\text { Sahariana }\end{array}$ & $\begin{array}{l}\text { As barreiras de entrada ao trabalho não } \\
\text { agrícola remunerado são ainda maiores } \\
\text { para as mulheres }\end{array}$ \\
\hline Perry e Ahearn (1994) & $\begin{array}{l}\text { Off-Farm } \\
\text { Work }\end{array}$ & Indivíduo & EUA & $\begin{array}{l}\text { Contribuição crescente das mulheres na } \\
\text { renda domiciliar rural, sobretudo quando } \\
\text { combinadas atividades dentro e fora do } \\
\text { domicílio }\end{array}$ \\
\hline
\end{tabular}


SILVEIRA BRAGA, BRAGA

\begin{tabular}{|c|c|c|c|c|}
\hline Yang (1997) & $\begin{array}{l}\text { Off-Farm } \\
\text { Work }\end{array}$ & Indivíduo & $\begin{array}{l}\text { Teórico, } \\
\text { aplicação } \\
\text { na China }\end{array}$ & $\begin{array}{l}\text { Cria um modelo teórico para observar } \\
\text { Efeitos do trabalho off-farm sobre o } \\
\text { nível educacional, mostrando que existe } \\
\text { um efeito spillover associado }\end{array}$ \\
\hline Lee (1998) & $\begin{array}{l}\text { Off-Farm } \\
\text { Work }\end{array}$ & Indivíduo/Estabelecimento & Teórico & $\begin{array}{l}\text { Tese de doutorado dedicada em } \\
\text { construção de modelos teóricos e } \\
\text { aplicações para impactos regionais na } \\
\text { Europa do trabalho off-farm }\end{array}$ \\
\hline Huffman (2006) & $\begin{array}{l}\text { Off-Farm } \\
\text { Work }\end{array}$ & Indivíduo/Estabelecimento & Teórico & $\begin{array}{l}\text { Modelo para avaliar o papel do capital } \\
\text { humano sobre a decisão das famílias de } \\
\text { performarem atividades off-farm }\end{array}$ \\
\hline Lima (2008) & $\begin{array}{l}\text { Pluriatividade, } \\
\text { trabalho não } \\
\text { agrícola }\end{array}$ & Domicílio & $\begin{array}{l}\text { Brasil } \\
\text { (Nordeste) }\end{array}$ & $\begin{array}{l}\text { Fontes de renda exclusivamente não } \\
\text { agrícolas e pluriatividade seriam } \\
\text { responsáveis para a redução da } \\
\text { pobreza e desigualdade rural }\end{array}$ \\
\hline Ney e Hoffmann (2008) & $\begin{array}{l}\text { Rendas } \\
\text { agrícolas e } \\
\text { não agrícolas }\end{array}$ & Domicílio & Brasil & $\begin{array}{l}\text { Ocupações agrícolas e não-agrícolas } \\
\text { contribuem, respectivamente, para a } \\
\text { redução e para o aumento das } \\
\text { disparidades de rendimentos no meio } \\
\text { rural brasileiro }\end{array}$ \\
\hline Moreira (2010) & $\begin{array}{l}\text { Pluriatividade, } \\
\text { trabalho não } \\
\text { agrícola }\end{array}$ & Domicílio & $\begin{array}{l}\text { Brasil } \\
\text { (Sudeste) }\end{array}$ & $\begin{array}{l}\text { Fontes de renda não agrícolas são } \\
\text { responsáveis para a redução da } \\
\text { pobreza e desigualdade rural, } \\
\text { especialmente quando realizada } \\
\text { conjuntamente (pluriatividade) }\end{array}$ \\
\hline Haiguang, Xiubin e Jiping (2013) & $\begin{array}{l}\text { Part time } \\
\text { farming }\end{array}$ & Estabelecimento & China & $\begin{array}{l}\text { Utilizaram das rendas não agrícolas } \\
\text { para classificar os domicílios como part } \\
\text { ou full time farms }\end{array}$ \\
\hline Vanwey e Vithayathil (2013) & $\begin{array}{l}\text { Off-Farm } \\
\text { Work }\end{array}$ & Estabelecimento & $\begin{array}{l}\text { Amazônia } \\
\text { brasileira }\end{array}$ & $\begin{array}{l}\text { Os efeitos do trabalho off-farm são } \\
\text { distintos para homens e mulheres ao } \\
\text { passo que existem divisões do trabalho } \\
\text { reprodutivo e reprodutivo }\end{array}$ \\
\hline
\end{tabular}




\begin{tabular}{|c|c|c|c|c|}
\hline Escher et al. (2015) & Pluriatividade & Estabelecimento & Brasil & $\begin{array}{l}\text { Caracterização da Pluriatividade e dos } \\
\text { plurirendimentos no Brasil, } \\
\text { apresentando diferentes unidades de } \\
\text { análises e conceitos }\end{array}$ \\
\hline Neudert et al. (2015) & $\begin{array}{l}\text { Off-Farm } \\
\text { Work }\end{array}$ & Domicílio & Madagascar & $\begin{array}{l}\text { Mostram como a diversificação de } \\
\text { renda, educação e saúde se relacionam } \\
\text { para geração do bem estar, reforçando } \\
\text { a importância de estratégias de } \\
\text { adaptação }\end{array}$ \\
\hline Gautam e Andersen (2016) & Diversificação & Domicílio & Nepal & $\begin{array}{l}\text { Diversificação agrícola por si só afeta o } \\
\text { bem-estar, mas sim os ganhos } \\
\text { monetários advindos da mesma }\end{array}$ \\
\hline $\begin{array}{l}\text { Sakamoto, Nascimento e Maia } \\
(2016)\end{array}$ & $\begin{array}{l}\text { Pluriatividade, } \\
\text { trabalho não } \\
\text { agrícola }\end{array}$ & Domicílio & Brasil & $\begin{array}{l}\text { Buscam avaliar o papel de rendas } \\
\text { agrícolas e não agrícolas, mas } \\
\text { enfrentam dificuldades para classificar } \\
\text { as famílias pluriativa }\end{array}$ \\
\hline Tocco, Davidova e Bailey (2016) & $\begin{array}{l}\text { Part time } \\
\text { farming }\end{array}$ & Indivíduo & Itália & $\begin{array}{l}\text { Utilizam o termo part time farming, mas } \\
\text { trata como sinônimo de pluriatividade e } \\
\text { multiple job holding para estudar a } \\
\text { influência do tamanho da propriedade }\end{array}$ \\
\hline Su et al. (2016) & $\begin{array}{l}\text { Off-Farm } \\
\text { Work }\end{array}$ & Indivíduo & China & $\begin{array}{l}\text { Maior inserção das mulheres em } \\
\text { atividades off-farm negando a existência } \\
\text { de uma feminização da agricultura }\end{array}$ \\
\hline Rocha (2017) & Pluriatividade & Estabelecimento & $\begin{array}{l}\text { Brasil } \\
\text { (Sudoeste } \\
\text { Baiano) }\end{array}$ & $\begin{array}{l}\text { Estendeu o conceito de unidade } \\
\text { domiciliar para levantamento de dados } \\
\text { primários e caracterizar famílias } \\
\text { pluriativas }\end{array}$ \\
\hline Van den Broeck e Maertens (2017) & $\begin{array}{l}\text { Off-Farm } \\
\text { Work }\end{array}$ & Indivíduo & Senegal & $\begin{array}{l}\text { Para as mulheres acima da linha da } \\
\text { pobreza existe um efeito negativo } \\
\text { associado a sobrecarga de trabalho e } \\
\text { insatisfação com a atividade exercida }\end{array}$ \\
\hline
\end{tabular}




\begin{tabular}{|l|l|l|l|l|}
\hline Silva, Freitas e Costa (2018) & Pluriatividade & Estabelecimento & Brasil & $\begin{array}{l}\text { Estabelecimentos que se dedicavam a } \\
\text { atividades exclusivamente agrícolas } \\
\text { eram tecnicamente mais eficientes em } \\
\text { relação aqueles pluriativos }\end{array}$ \\
\hline
\end{tabular}




\section{Considerações Finais}

Este trabalho teve como objetivo relacionar os termos mais comum referentes à diversificação do trabalho rural. Especificamente, deu-se atenção ao embate dos termos de agricultura em tempo parcial (part time farming) e pluriatividade, que possuem conotações e aplicações distintas dado o recorte histórico e conjuntura econômica de quando emergem. Não menos importante, outros termos são recorrentes no campo de estudo do tema, como o exercício do trabalho off-farm e dos trabalhos exclusivamente não agrícolas, por exemplo. Deve-se pontuar, ainda, que dentro do campo da diversificação de trabalhos rurais, existem atividades não agrícolas realizadas dentro dos domicílios que, apesar de estarem compreendidas dentro do campo da pluriatividade, é deixada de lado na grande parte da literatura abordada.

A mudança mais significativa dos termos se dá quando da transição dos conceitos de part time farming para pluriatividade. Neste caso, de fato, o primeiro se torna obsoleto na medida em que as dinâmicas econômicas e sociais se alteram devido às mudanças nas estruturas produtivas, enquanto o segundo incorpora outras dimensões e amplia a possibilidade de análises. Não obstante, é possível que diferentes termos citados coexistam nos trabalhos a depender dos objetivos das pesquisas.

A utilização dos termos distintos é determinado pelas diferentes óticas de análise, sejam elas temporais ou espaciais. De qualquer forma, os membros dos domicílios que buscam pela diversificação laboral não podem, por um lado, serem tratados como meros diletantes nem, por outro, como uma escolha aleatória (apesar de os dois extremos poderem existir, fruto de falhas de mercado ou falta de políticas públicas de garantia de bem estar rural, por exemplo). A realização das atividades off-farm são, na verdade, fruto da racionalização dos agentes na busca de maximização das suas utilidades, considerando aumento renda, novas oportunidades de aprendizado, acumulação de capital físico e humano, dentre outros.

Isto posto, existe uma evidente dificuldade na literatura atual em determinar a partir de um único termo, o fenômeno que faz com que os indivíduos exerçam atividades não agrícolas ou, ainda, exerçam atividades agrícolas fora de sua propriedade. Por outro lado, existe uma nítida divisão a partir da unidade de análise: enquanto o termo pluriatividade é utilizado para as pesquisas em nível domiciliar (ou 
de estabelecimento), o termo off-farm analisa sobretudo as relações individuais de trabalho. Deste modo, aponta-se a importância dos trabalhos empíricos de estabelecerem coerente relação entre a escolha da abordagem teórica e metodológica com a unidade de analise a ser utilizada.

\section{REFERÊNCIAS}

ANJOS, F. S. DOS. Pluriatividade e ruralidade: enigmas e falsos dilemas. Estudos Sociedade e Agricultura, v. 9, n. 2, p. 54-80, 2001.

BRYDEN, J.; FULLER, T. Farm Structures and Pluriactivity Research Programme:

Pluriactivity as a Rural development option. The Arkleton Trust (Research) Ltd, n. 1-21, 1988.

CARNEIRO, M. J. Pluriactivité agricole: l'héterogénéité cachée. Cahiers d'économie et sociologie rurales, v. 1, n. 38, 1996.

CARTER, S. THE ROLE OF FARMS IN RURAL BUSINESS DEVELOPMENT. [S.I.] Stirling University, 1997.

ESCHER, F. et al. Caracterização da pluriatividade e dos plurirrendimentos da agricultura brasileira a partir do Censo Agropecuário 2006. Revista de Economia e Sociologia Rural, v. 52 , n. 4, p. 643-668, 2015.

FULLER, A. M. PART TIME FARMING AND THE FARM FAMILY:A NOTE FOR FUTURE RESEARCH. Sociologia Ruralis, v. 23, n. 1, p. 5-10, abr. 1983.

HUFFMAN, W. E. Farm and Off-Farm Work Decisions: The Role of Human Capital. The Review of Economics and Statistics, v. 62, n. 1, p. 14, fev. 2006.

HUFFMAN, W. E.; LANGE, M. D. Off-Farm Work Decisions of Husbands and Wives: Joint Decision Making. The Review of Economics and Statistics, v. 71, n. 3, p. 471, ago. 1989.

KAUTSKY, K. A questão Agrária. 3. ed. São Paulo: Proposta Editorial Ltda., 1980.

KIMHI, A. Farm and Off-Farm Work Including the Option of Full-Time Off-Farm Work. Journal of Agricultural Economics, v. 45, n. 1991, p. 232-239, 1994.

$\mathrm{KIMHI}$, A. Is Part-Time Farming Really a Step in the Way Out of Agricultural? American Journal of Agricultural Economics, v. 82, n. 1, p. 38-48, fev. 2000.

LIMA, J. R. F. Efeitos da pluriatividade e rendas não-agrícolas sobre a pobreza e desigualdade rural na região Nordeste. [s.l.] Universidade Federal de Viçosa, 2008.

NEVES, D. P. Agricultura familiar e mercado de trabalho. Estudos Sociedade e Agricultura, v. 8, n. abril, p. 7-24, 1997.

NEWBY, H. Emergent issues in Theories of Agrarian Development. European Economic Conunity: [s.n.].

OECD. Part-time farming in OECD countries: general report. [s.l: s.n.].

PIEDRA-BONILLA, E. B.; CUNHA, D. A.; BRAGA, M. J. Diversificação agrícola na bacia hidrográfica do Rio das Contas, Bahia. Geosul, v. 34, n. 72, p. 280-306, 2019. 
ROBSON, N.; GASSON, R.; HILL, B. PART TIME FARMING-IMPLICATIONS FOR FARM FAMILY INCOME. Journal of Agricultural Economics, v. 38, n. 2, p. 167-192, maio 1987.

SARRACENO, H. II Part Time Nell'Agricultura dei Paesi Occidentalli: linee evolutive e strumenti di intervento. La Questione Agraria, n. 18, 1985.

SCHNEIDER, S. O Desenvolvimento Agrícola e as Transformações da Estrutura Agraria nos Países Desenvolvidos: a pluriatividade. Revista Reforma Agrária, v. 24, n. 03, p. 106-132, 1994.

SCHNEIDER, S. Teoria social, agricultura familiar e pluriatividade. Revista Brasileira de Ciências Sociais, v. 18, n. 51, p. 7-36, 2003.

SCHNEIDER, S. A pluriatividade na agricultura familiar. 2. ed. Porto Alegre: Editora da UFRGS, 2009.

SHUCKSMITH, D. M. et al. PLURIACTIVITY, FARM STRUCTURES AND RURAL CHANGE. Journal of Agricultural Economics, v. 40, n. 3, p. 345-360, set. 1989.

SOARES, J. A. P.; PEIXINHO, D. M. Pluriatividade em assentamentos rurais: forma de exclusão, inclusão ou permanência no campo? Ateliê Geográfico, v. 13, n. 2, p. 187-207, 20 ago. 2019.

START, D. The Rise and Fall of the Rural Non-farm Economy: Poverty Impacts and Policy Options. Development Policy Review, v. 19, n. 4, p. 491-505, 2001.

SUMNER, D. A. The Off-Farm Labor Supply of Farmers. American Journal of Agricultural Economics, v. 64, n. 3, p. 499-509, 1982.

\section{NOTAS DE AUTOR}

\section{CONTRIBUIÇÃO DE AUTORIA}

Cicero Augusto Silveira Braga - Concepção. Coleta e análise de dados, Elaboração do manuscrito, revisão e aprovação da versão final do trabalho

Marcelo José Braga - Concepção e participação ativa da discussão dos resultados; Revisão e aprovação da versão final do trabalho.

\section{FINANCIAMENTO}

O presente trabalho foi realizado com apoio da Coordenação de Aperfeiçoamento de Pessoal de Nível Superior Brasil (CAPES) - Código de Financiamento 001

\section{CONSENTIMENTO DE USO DE IMAGEM}

Não se aplica.

\section{APROVAÇÃO DE COMITÊ DE ÉTICA EM PESQUISA}

Não se aplica.

\section{CONFLITO DE INTERESSES}

Não se aplica.

\section{LICENÇA DE USO}

Este artigo está licenciado sob a Licença Creative Commons CC-BY. Com essa licença você pode compartilhar, adaptar, criar para qualquer fim, desde que atribua a autoria da obra.

\section{HISTÓRICO}

Recebido em: 28-08-2020

Aprovado em: 15-11-2021 